\title{
Correction to: Income Inequality, Socio-Economic Status, and Residential Segregation in Greater Cairo: 1986-2006
}

Abdelbaseer A. Mohamed and David Stanek

Correction to:

Chapter 3 in: M. van Ham et al. (eds.), Urban Socio-Economic Segregation and Income Inequality, The Urban Book Series, https://doi.org/10.1007/978-3-030-64569-4_3

The original version of the book was published with incorrect figure 3.3. The chapter and book have been updated with the changes. 

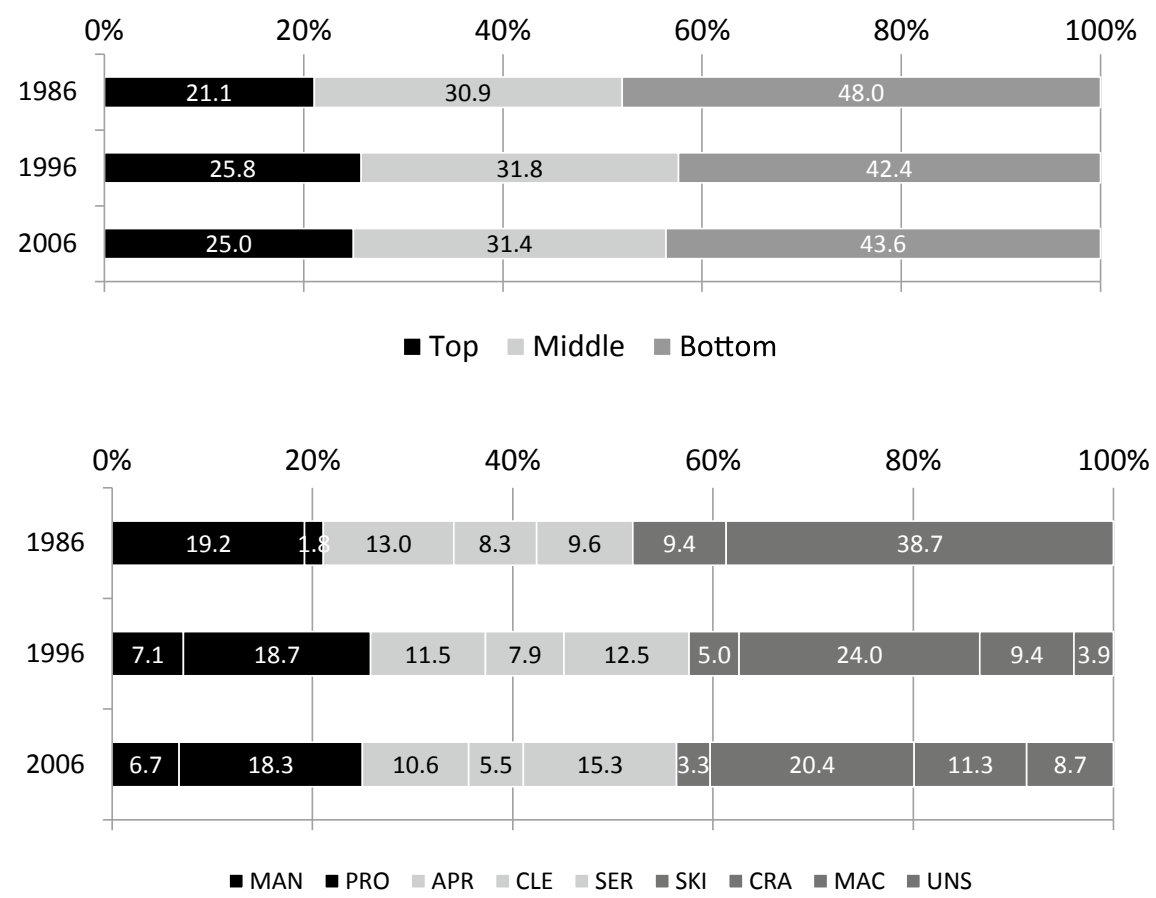

Fig. 3.3 Distribution of occupational groups and change over time 